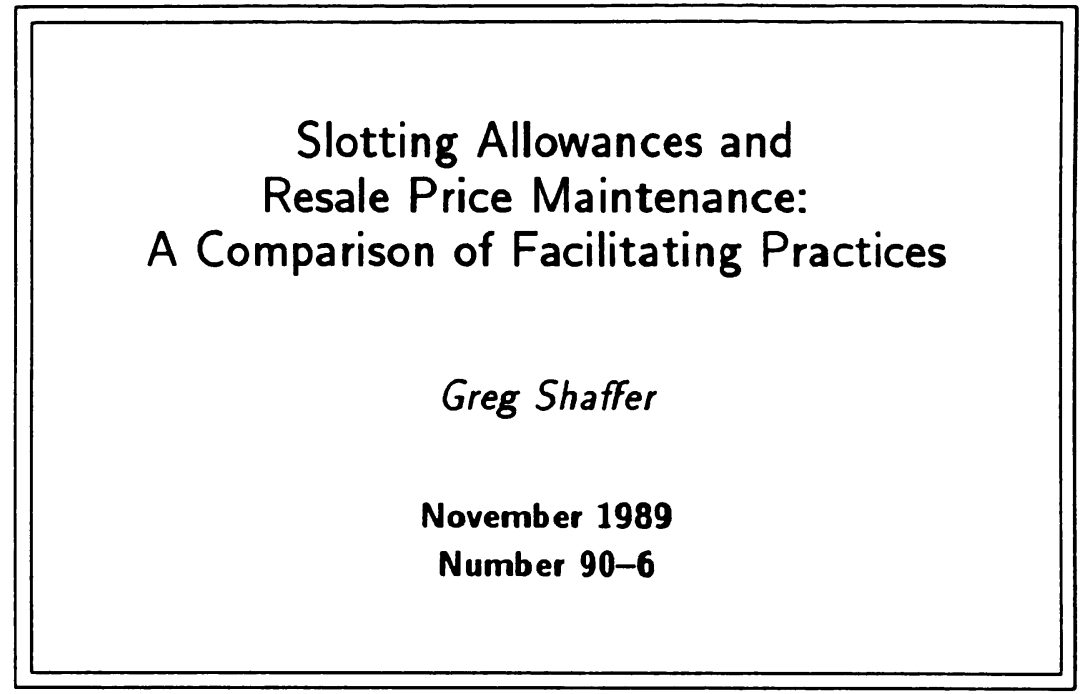

DEPARTMENT OF ECONOMICS University of Michigan Ann Arbor, Michigan 48109
The Sumner and Laura Foster Librany The University of fichigan 



\title{
Slotting Allowances and Resale Price Maintenance: A Comparison of Facilitating Practices
}

\author{
Greg Shaffer* \\ Department of Economics \\ University of Michigan
}

November 1988

Revised: November 1989

\begin{abstract}
Producers in a perfectly competitive industry compete to obtain shelf space at the retail level. Barring contract observability problems, slotting allowances are observed in equilibrium. Producers charge a high wholesale price, but give back their profits via up-front payments to retailers. However, if the individual supplier - retailer wholesale price terms are unobservable by competitors, then resale price maintenance will be seen, but the coverage will not be universal.

The equilibria can be ranked by the usual social welfare criteria. Resale price maintenance, though worse than simple marginal cost wholesale pricing, yields greater surplus than the slotting allowance equilibrium.
\end{abstract}

*I would like to thank Robert Willig, Carl Shapiro, seminar participants at Purdue, Dartmouth, Cornell, Yale and Michigan, and two anonymous referees for their helpful comments. I am grateful to the Olin Program for the Study of Economic Organization and Public Policy for providing research support. 



\section{Introduction}

Shelf space at the retail level is becoming increasingly scarce. Although the number of products sold by the average grocery store has grown from 11,800 to 20,000 in the last ten years, the number of new product introductions has increased from 2,600 per year in 1978 to 10,200 per year in $1987 . .^{1}$ Retailers are now confronted by more product categories and more brands per category than ever before. ${ }^{2}$

Coupled with high local retailing concentration, this product proliferation has shifted the balance of power away from manufacturers and led to increased competition among producers for the limited amount of store space. ${ }^{3}$ Evidence of such competition may be inferred from the growing incidence of slotting allowances (shelf space rental fees) during the past decade. This practice, and the use of resale price maintenance (RPM) to obtain shelf space, will be the focus of this paper.

Slotting allowances, also known as street money or placement allowances, are fees paid by manufacturers to obtain retailer patronage. They may be cash gifts or payments in kind, such as cases of free goods. Either way, their salient characteristic is that the fee paid does not vary with subsequent retailer sales.

Although payment of fees to retailers has been documented at least as far back as the A \& $\mathrm{P}$ case in the 1930 's, and free cases of goods as well as other forms of shelf space rivalry have been around for a long time, there seems to have been an increase in the magnitude of

\footnotetext{
${ }^{1}$ Chicago Tribune (1988).

${ }^{2}$ For example, in the Los Angeles area alone, there are 15 varieties of green peas, 19 different kinds of mustard, 12 brands of frozen pizza, etc., all vying for shelf space.

${ }^{3}$ Porter (1976) estimates that an average of two to five retailers per industry operate in any given local market. A wave of mergers since then has further increased concentration. See Johnson (1987), chapters 4 and 8.
} 
the allowances during the last ten years. ${ }^{4}$ Unfortunately these fees are negotiated orally and in private and hence public data is non-existent. However recent trade press articles quote industry sources suggesting the practice accounts for $1 / 3$ to $1 / 2$ of the $\$ 19$ billion spent by producers on trade promotions in 1987. Some warehouses and grocery chains are said to be demanding up to $\$ 100,000$ for each product stocked. ${ }^{5}$ The shelf space shortage appears to be most acute among frozen foods, dairy products, and microwavable shelf stable foods.

RPM, a restraint imposed by a manufacturer on his dealers which restricts the price at which his product may be resold, has been per se illegal since 1975. But because current economic theories of RPM are based on efficiency explanations such as information free riding and dealer service repair externalities, the Department of Justice recently argued in its amicus brief in the Spray-Rite v. Monsanto (1984) case that RPM was unsuitable for per se treatment. Furthermore, the Supreme Court's recent ruling in Business Electronics v. Sharp Electronics (1988) tacitly allows for products to be price maintained. ${ }^{6}$

One of the themes of this paper is that RPM is consistent with shelf space rivalry. In providing a means for retailers to commit contractually to high prices, a manufacturer can indirectly raise retailer profits by eliminating their incentive for aggressive downstream pricing. Although manufacturers would prefer lower retail prices and higher sales, the competition among themselves for the scarce shelf space provides the incentive for such contracts. Unlike the free - riding and dealer repair service theories, this explanation does not rely on the complexity of the product. When it was legal, the practice was used for both technical products

\footnotetext{
${ }^{4}$ Perhaps this is due to the Reagan administration's lenient interpretation and enforcement of the price discrimination laws.

${ }^{5}$ See Advertising Age (1987) and the Wall Street Journal (1988).

${ }^{6}$ The court ruled that a manufacturer's agreement with high - priced dealers to stop supplying discounters is not necessarily an antitrust violation. See New York Times (1988).
} 
as well as convenience goods, with the majority of items having been sold in drug stores and supermarkets.

This paper provides an equilibrium analysis of both RPM and slotting allowances. Each practice serves to increase retailer profits. At first blush, shelf space rental fees appear to be innocuous since pure transfers of profit between industries have no welfare consequence. However this implicitly assumes that the sum of producer and retailer industry profits is fixed. In general this will not be true. Manufacturers are in competition with each other to obtain retailer patronage and retailers compete among themselves to obtain customer favor. Slotting allowances, by lessening competition at the retail level, serve to increase the profit pie. Since manufacturers must earn non-negative profits, slotting allowance contracts coincide with per-unit wholesale prices which are above production marginal cost. Retailers who sign such contracts not only receive a direct up-front payment but also benefit indirectly from the reduced downstream price competition. By committing to a relatively high wholesale cost, a retail firm essentially announces its intention to be less aggressive in its pricing. Other firms are induced to raise their retail prices and the original firm gains through the feedback effects. $^{7}$

The main thrust of this paper is that RPM and slotting allowances may have anticompetitive effects. Since both are contractual provisions which can raise retailer prices and profits, they may be added to the class of facilitating practices. ${ }^{8}$ The sine qua non of these practices is the profitability of the independent rational reactions of one's rivals. In the slotting allowances case, each manufacturer raises the wholesale price to his retailer thereby commiting

\footnotetext{
${ }^{7}$ This is the familiar puppy - dog strategy. See Fudenburg and Tirole (1984). I'm assuming of course, that price reaction functions are upward sloping. If not, then rivals will react by lowering their prices. Such a response would lower the profits of the firm signing the slotting allowance contract.

${ }^{8}$ See Salop (1986) for a general overview.
} 
her to less aggressive retail pricing. With legalized RPM, a retailer commits herself directly to a retail price by choosing a price maintained product. In both cases rivals act on this information in such a way as to raise profits for all. In a pricing game with upward sloping reaction functions, commitment to a relatively high price induces each rival to raise her own price. Their price increases then have positive first order feedback effects on the first firm's profit.

Similar models are found elsewhere. In the principal - agent literature, Fershtman and Judd (1984) show that non-cooperative owners can write compensation contracts for their managers in such a way as to increase firm profits above the pre-contract Nash equilibrium. Similarly, Bonanno and Vickers (1988) have shown that vertical separation dominates integration when manufacturers can set two - part tariffs and extract all the rent. Likewise it is well known that sham innovations can be cross - licensed to achieve the collusive outcome. ${ }^{9}$ In addition to identifying slotting allowances and RPM as facilitating practices, I am also able to rank the pair in terms of social welfare. Retailer prices and profits are found to be higher with slotting allowances than with RPM. Furthermore, if RPM is observed, prices and profits at the retail level will be greater when the coverage is incomplete, i.e. when not all brands are price maintained. The result that downstream prices and profits are greater when retailers commit to high marginal costs rather than to high prices directly seems somewhat surprising.

RPM is an example of a contractual provision which inhibits a firm from reacting to her competitors. Any retailer who chooses a price maintained product has tied her hands regardless of her opponents' choice of prices. In a downstream duopoly, if both retailers

\footnotetext{
${ }^{9}$ See Shapiro 1985.
} 
choose RPM, neither can respond to the other's commitment. At equilibrium, prices and profits are at the non-strategic Bertrand Nash outcome. If only one firm chooses RPM, the other retains pricing flexibility. Industry prices and profits increase and welfare declines. ${ }^{10}$ If neither firm chooses RPM, both retailers have the ability to react strategically to their rival. In the slotting allowances case, both firms sign contracts with high marginal costs and both firms retain their pricing flexibility. This combination accounts for the relatively higher profits and poorer welfare performance of this practice.

This chapter is organized in the following manner. Section ii presents the formal model. Section iii derives the benchmark case where neither practice is allowed. Sections iv through vi examine the two practices individually and in conjunction. Here I find that shelf space rental fees lead to higher retail prices and profits and hence lower welfare performance than RPM. Section vii summarizes the welfare results and explores the extent to which prices can be raised in a linear demand framework. Section viii concludes with a policy discussion of the implications of this research.

\section{The Model}

Consider a market for a homogeneous product which is produced by a perfectly competitive manufacturing industry and sold by a differentiated retail duopoly. ${ }^{11}$ Retailers are differentiated in the sense that even though the product they sell is homogeneous, customers differ in their store preference. Thus unequal retail prices do not cause demand at the higher priced store to fall to zero. One familiar model in the literature is that of spatial competition.

\footnotetext{
${ }^{10}$ The outcome is similar to a Stackelberg price leader game.

${ }^{11}$ The model would work equally well if $I$ assumed a large number of symmetrically differentiated suppliers vying for one available slot at each store. Competition among the upstream firms would ensure that no producer could earn positive profit in equilibrium.
} 
Consumers are located between the two stores and incur positive transportation costs when they buy. Here retailers are differentiated in a spatial sense. This is one justification for the assumption, but there is no need to limit oneself to this explanation. Casual observation should confirm that consumers have store preference. They may prefer store i's layout, parking, carpet, music, sales personnel, etc. , or they may desire multiple products only some of which store $\mathrm{j}$ has. However, not all consumers agree on their store preferences. ${ }^{12}$

Manufacturers compete to gain access to the retail level. I assume they are unable to set up shop and sell independently. This is descriptive since most consumer goods are sold through multiproduct retail outlets where overhead costs are diffused. Opening a single item outlet would be prohibitively costly.

The precise form of the allowable supplier contracts will matter greatly in the ensuing game. Attention is restricted to contracts which are not contingent on rival suppliers' prices or quantities. Such contracts would almost surely be violating antitrust laws on horizontal price fixing. Quantity discounts are allowed in the form of a two-part tariff. A negative fixed fee corresponds to the slotting allowances observed in practice. In addition each producer has the option to write a contract stipulating his product's resale price. Finally producers may specify a clause prohibiting rival products from being sold at the same retail outlet. ${ }^{13}$

The game is played in three stages. In the first stage manufacturers simultaneously announce the terms of their sales contracts. This will involve specifying the unit wholesale price, the fixed fee coupled with the sole supplier clause, and the maintained price, if any. Retailers then choose which producer to buy from and in the last stage compete in a non-

\footnotetext{
${ }^{12}$ A large marketing literature exists on retailer differentiation strategies. See Johnson (1987) for a survey.

${ }^{13}$ This last assumption is necessary to legally prohibit the retailer from accepting slotting allowances but then not stocking the manufacturer's product. Without this restriction, suppliers would not offer negative fixed fees, since in a static one - shot game retailers cannot be trusted.
} 
cooperative pricing game. Players at each stage choose their actions knowing the effects of such actions on all succeeding stages. All information is common knowledge.

\section{Demand Specification and Notation}

Assumption 1 : Retail demand functions $D^{i}(P)$ are differentiable, downward sloping, substitutes, and they satisfy the definiteness property.

$$
D_{i}^{i}<0, \quad D_{j}^{i}>0, \quad D_{i}^{i} D_{j}^{j}-D_{j}^{i} D_{i}^{j} \geq 0
$$

where $P=\left(P_{1}, P_{2}\right)$ is the vector of retail prices. Superscripts above the demand function denote the retailer while subsripts indicate partial derivatives with respect to prices.

Assumption 2: Let $w_{i}$ be the per unit wholesale cost and $F_{i}$ be the fixed fee specified in the contract with retailer i's supplier. Then retailer i's profit is given by $\pi^{i}\left(P ; w_{i}, F_{i}\right)=$ $\left(P_{i}-w_{i}\right) D^{i}(P)-F_{i}$. Furthermore let $\Delta=\pi_{i i}^{i} \pi_{j j}^{j}-\pi_{i j}^{i} \pi_{j i}^{j}$. I will assume

$$
\pi_{i i}^{i}<0, \quad \pi_{i j}^{i}>0, \quad \Delta>D_{j}^{i} \pi_{j i}^{j}
$$

where the subscripts denote partial derivatives with respect to prices. The first condition is necessary for profit maximization. The second condition states that a firm's marginal profit increases with her rival's price. This is critical to the analysis for it ensures that Bertrand reaction functions slope upward. The last condition not only guarantees uniqueness of the Nash equilibrium, ${ }^{14}$ it also ensures that absent fixed fee transfers between a manufacturer and his retailer, each retailer's equilibrium profit will be decreasing in her marginal cost $w .^{15}$ Assumption 3 : Let $c$ be the manufacturer's constant unit production cost. Then the supplier $k$ who sells to retailer $i$ will earn profit denoted by $\pi^{k}\left(w_{i}, F_{i}\right)=\left(w_{i}-c\right) D^{i}(P)+F_{i}$.

\footnotetext{
${ }^{14}$ See Friedman (1983).

${ }^{15}$ This condition is satisfied with linear demands. In that case $\pi_{i i}^{i}=2 D_{i}^{i}, \pi_{i j}^{i}=D_{j}^{i}, \pi_{j i}^{j}=D_{i}^{j}$, and $\pi_{j j}^{j}=2 D_{j}^{j}$. Then $\left(D_{j}^{i} \pi_{j i}^{j}-\Delta\right)=2 D_{j}^{i} D_{i}^{j}-4 D_{i}^{i} D_{j}^{j}<0$ by assumption 1 .
} 


\section{No RPM , No Slotting Allowances}

In this section I derive equilibrium prices and profits assuming that RPM is illegal and that producers are unwilling or unable to set fixed fee transfers $\left(F_{i}=0\right)$. This case will be the standard for future comparisons when these assumptions are relaxed.

Consider the stage-three pricing game. Each retailer chooses a supplier with a corresponding wholesale price. The first order conditions for profit maximization are given by $\pi_{i}^{i}=\left(P_{i}-w_{i}\right) D_{i}^{i}+D^{i}=0$ where the arguments of the demand function have been omitted for brevity. From the assumptions, there exists a unique equilibrium in prices. Denote the equilibrium price and profit vector when both retailers retain their pricing flexibility as

$$
P^{B B}=\left(P_{1}^{B B}\left(w_{1}, w_{2}\right), P_{2}^{B B}\left(w_{1}, w_{2}\right)\right), \quad \Pi^{B B}=\left(\pi^{1}\left(P^{B B} ; F_{1}=0\right), \pi^{2}\left(P^{B B} ; F_{2}=0\right)\right)
$$

Now look at the first two stages. To obtain shelf space at store $i$, a manufacturer must offer the retailer a contract which will yield her at least as much in profit as she could get by stocking another supplier's product. At the same time, the manufacturer will not offer a contract which earns him negative profit. In equilibrium retailer $i$ will choose to purchase from a supplier who sets $w$ to solve

$$
\max \left(P_{i}^{B B}-w_{i}\right) D^{i}\left(P^{B B}\right) \quad \text { s.t. } \quad\left(w_{i}-c\right) D^{i}\left(P^{B B}\right) \geq 0
$$

Proposition 1 The equilibrium supplier contract has the transfer wholesale price equal to supplier marginal cost $\left(w_{i}=c\right)$.

Proof : Set up the Lagrangian function and solve. It is easy to check that $w_{i}=c$ will satisfy the Kuhn - Tucker conditions. Using assumption 2 , it can be shown that $w_{i}$ cannot exceed $c$. Wholesale prices less than $c$ violate the non-negative manufacturer profit constraint. Q.E.D. 
Since the upstream industry is perfectly competitive, no manufacturing firm will be able to make positive profit. Any firm whose selling contract yielded it strictly positive profit would lose retailer patronage because another upstream firm would be able to offer the retailer higher profits by lowering his wholesale price. Thus the downstream firms have all of the bargaining power and therefore will be able to extract all of the channel profit.

Denote the equilibrium price vector in the benchmark case as $P^{B}=\left(P_{1}^{B B}(c, c), P_{2}^{B B}(c, c)\right)$ and the profit vector $\Pi^{B}=\left(\pi^{1}\left(P^{B} ; F_{1}=0\right), \pi^{2}\left(P^{B} ; F_{2}=0\right)\right)$.

\section{Slotting Allowances, No RPM}

Now allow fixed fees. ${ }^{16}$ There is no restriction on their sign. The manufacturers announce two-part tariff contracts subject only to earning non-negative profits. The retail pricing game looks exactly as it did in the previous section. Retailer i's profit is given by $\left(P_{i}-w_{i}\right) D^{i}(P)-F_{i}$ and the corresponding first order condition is $\pi_{i}^{i}=\left(P_{i}-w_{i}\right) D_{i}^{i}+D^{i}=0$. This yields $P^{B B}=\left(P_{1}^{B B}\left(w_{1}, w_{2}\right), P_{2}^{B B}\left(w_{1}, w_{2}\right)\right)$.

In stage two each retailer will purchase from the supplier who enables her to earn the highest profit. In equilibrium the supplier chosen by retailer $i$ will be the one who has set $(w, F)$ to maximize his retailer's profit taking as given the other retailer's sales contract and subject to earning non-negative profit.

$$
\max _{w_{i}, F_{i}}\left(P_{i}^{B B}-w_{i}\right) D^{i}\left(P^{B B}\right)-F_{i} \quad \text { s.t. } \quad\left(w_{i}-c\right) D^{i}\left(P^{B B}\right)+F_{i} \geq 0
$$

Differentiating with respect to $w$ and simplifying gives

$$
\left[\left(P_{i}^{B B}-c\right) D_{i}^{i}+D^{i}\right] \frac{\partial P_{i}^{B B}}{\partial w_{i}}+\left(P_{i}^{B B}-c\right) D_{j}^{i} \frac{\partial P_{j}^{B B}}{\partial w_{i}}=0
$$

\footnotetext{
${ }^{16}$ For a similar analysis see Bonanno and Vickers (1988). These authors have essentially derived Propositions 2 and 3 in the context of an upstream duopoly who sell to independent homogeneous retailers.
} 
Substituting the retailer's profit maximizing condition for the term in brackets gives

$$
\left(w_{i}-c\right) D_{i}^{i} \frac{\partial P_{i}^{B B}}{\partial w_{i}}+\left(P_{i}^{B B}-c\right) D_{j}^{i} \frac{\partial P_{j}^{B B}}{\partial w_{i}}=0
$$

By assumption $1, D_{i}^{i}<0$ and $D_{j}^{i}>0$. By totally differentiating the stage three retailer first order conditions, one can show

$$
\frac{\partial P_{i}^{B B}}{\partial w_{i}}=\frac{D_{i}^{i} \pi_{j j}^{j}}{\Delta}>0, \quad \frac{\partial P_{j}^{B B}}{\partial w_{i}}=-\frac{D_{i}^{i} \pi_{j i}^{j}}{\Delta}>0
$$

Thus (4) can be separated into the negative direct effect of the loss in profit due to firm i's own price increase, and the indirect positive effect in firm i's profits due to firm j's price increase.

Proposition 2 The equilibrium supplier contract when two-part tariffs are allowed has $w_{i}>$ $c$ and $F_{i}<0 .{ }^{17}$

Proof: Suppose not. Then there are two cases to consider. Suppose $w_{i}=c$. Then the first term in (4) equals zero. But the second term is positive. Therefore $w_{i} \neq c$. Suppose $w_{i}<c$. Then the first term in (4) is greater than zero. But this can only be a solution if $P_{i}^{B B}<c$, making the second term negative. If $P_{i}^{B B}<c$, then $F_{i}$ must be less than zero for the retailer to be making profit. But then $w_{i}<c$ and $F_{i}<0$ which violates the manufacturer's break even constraint. Q.E.D.

The intuition is straightforward. By committing herself to $w_{i}>c$, retailer i gives retailer j an incentive to raise her price. This has a positive first order effect on retailer i's profit. The lost revenue from each sale is returned to the retailer through the slotting allowance she receives. Retailer $\mathrm{j}$ has similar incentives. In equilibrium both retailers choose to commit

\footnotetext{
${ }^{17}$ See Bonanno and Vickers (1988), proposition 1.
} 
themselves to $w>c$. This enables them to raise their profits above the Nash level found in the previous section. See proposition 3 .

Let $w^{s}=\left(w_{1}^{s}, w_{2}^{s}\right)$ be the vector of Nash wholesale prices obtained in the slotting allowance equilibrium. Denote prices and profits by

$$
P^{S}=\left(P_{1}^{B B}\left(w_{1}^{s}, w_{2}^{s}\right), P_{2}^{B B}\left(w_{1}^{s}, w_{2}^{s}\right)\right), \Pi^{S}=\left(\pi^{1}\left(P^{S} ; F_{1}^{s}\right), \pi^{2}\left(P^{S} ; F_{2}^{s}\right)\right)
$$

Proposition 3 Retailer prices and profits are higher when manufacturers are able to use slotting allowances to obtain shelf space than when they are not. That is $P^{S}>P^{B}$ and $\Pi^{S}>\Pi^{B}{ }^{18}$

Proof: Since $\partial P_{j}^{B B} / \partial w_{i}$ and $\partial P_{i}^{B B} / \partial w_{i}>0$ and $w_{1}^{s}$ and $w_{2}^{s}>\mathbb{C}$,

$$
P_{1}^{S}=P_{1}^{B B}\left(w_{1}^{s}, w_{2}^{s}\right)>P_{1}^{B B}\left(w_{1}^{s}, c\right)>P_{1}^{B B}(c, c)=P_{1}^{B}
$$

and similarly $P_{2}^{S}>P_{2}^{B}$. To prove $\Pi^{S}>\Pi^{B}$, I first derive $\partial \pi^{i}\left(P^{B B}\right) / \partial w_{j}$.

$$
\partial \pi^{i}\left(P^{B B}\right) / \partial w_{j}=\left[\left(P_{i}^{B B}-w_{i}\right) D_{i}^{i}+D^{i}\right] \frac{\partial P_{i}^{B B}}{\partial w_{j}}+\left(P_{i}^{B B}-w_{i}\right) D_{j}^{i} \frac{\partial P_{j}^{B B}}{\partial w_{j}}
$$

By the first order condition for retailer profit maximization, the first term equals zero. Hence $\partial \pi^{i}\left(P^{B B}\right) / \partial w_{j}>0$ for all w. Now recall $\Pi_{1}^{S}=\pi^{1}\left(P_{1}^{B B}\left(w_{1}^{s}, w_{2}^{s}\right), P_{2}^{B B}\left(w_{1}^{s}, w_{2}^{s}\right) ; F_{1}^{s}\right)$. Therefore

$$
\Pi_{1}^{S}>\pi^{1}\left(P_{1}^{B B}\left(c, w_{2}^{s}\right), P_{2}^{B B}\left(c, w_{2}^{s}\right) ; F_{1}=0\right)>\pi^{1}\left(P_{1}^{B B}(c, c), P_{2}^{B B}(c, c) ; F_{1}=0\right)=\Pi_{1}^{B}
$$

where the first inequality is by the definition of Nash equilibrium, and the second inequality is true because $\partial \pi^{i}\left(P^{B B}\right) / \partial w_{j}>0$ as found above. A similar calculation shows $\Pi_{2}^{S}>\Pi_{2}^{B}$. Q.E.D.

This analysis relies critically on the ability of retailer $j$ to observe the details of retailer i's contract. Formally if $w_{i}$ is not observed, then $\partial P_{j}^{B B} / \partial w_{i}=0$ and the solution to (4) has

\footnotetext{
${ }^{18}$ See Bonanno and Vickers (1988), proposition 2.
} 
$w_{i}^{s}=c$. The game is played as if $w$ and $P$ were chosen simultaneously instead of sequentially.

Observability could be a serious problem, especially given the retailers' incentives to produce bogus contracts, showing artificially high w's. ${ }^{19}$

Similarly, this analysis assumes away enforcement costs associated with retailer moral hazard. Unrestricted cash bribes permit retailers to sign multiple contracts, collecting payments but selling only those goods which yield the greatest per-unit sale incentives. To prevent this, manufacturers will insist on a sole supplier arrangement. Even so, monitoring costs could be substantial. Explicit proof would be needed by third party enforcers. Inferential evidence such as a decline in the injured supplier's sales would not be acceptable. ${ }^{20}$

Thus whether slotting allowances are observed in practice depends on both the retailers' moral hazard and supplier monitoring costs as well as the observability of the supplier contracts.

\section{RPM, No Slotting Allowances}

In this section I allow contracts to include RPM, but assume fixed fees cannot be used. There are three possibilities: RPM is not observed; RPM is used by both retailers; or RPM is used by one retailer.

If RPM is not observed, then the results from section III apply. I found

$$
P^{B}=\left(P_{1}^{B B}(c, c), P_{2}^{B B}(c, c)\right), \quad \Pi^{B}=\left(\pi^{1}\left(P^{B} ; F_{1}=0\right), \pi^{2}\left(P^{B} ; F_{2}=0\right)\right)
$$

If RPM is observed at both stores, the stage three pricing game will be trivially determined. The retailers do, however, still choose from among the suppliers. An equilibrium

\footnotetext{
${ }^{19}$ See Katz (1986) for a critique of observable contracts.

${ }^{20}$ Alternatively, I could have analyzed contracts which allowed quantity forcing. Such a contract would specify a minimum sales transaction.
} 
in stage three is one in which neither retailer has an incentive to change suppliers given the other's choice. Thus the manufacturer who is stocked by retailer $\mathrm{i}$ will be the one who has chosen $(P, w)$ to maximize $i$ 's profit subject to his breakeven condition. Formally the problem is

$$
\max _{P_{i}, w_{i}}\left(P_{i}-w_{i}\right) D^{i}\left(P_{i}, P_{j}\right) \quad \text { s.t } \quad\left(w_{i}-c\right) D^{i}\left(P_{i}, P_{j}\right) \geq 0
$$

Solving for the Nash equilibrium of this system yields $w_{i}=c, P=P^{B}$ and $\Pi=\Pi^{B}$. This solution is precisely the same as the retailers' benchmark Nash equilibrium in their pricing game of section III. Without the use of fixed fees and the opportunity for strategic play that they give, two manufacturers simultaneously and non-cooperatively maximizing their retailer's profits can do no better than the retailers can themselves. Thus the case in which RPM is used by both retailers is equivalent to the benchmark case when neither RPM nor fixed fees were allowed.

Lastly, consider the case in which RPM is used at one outlet. Begin by considering the stage three pricing game for the firm not using RPM. Suppose firm 1 uses RPM. Retailer 2's maximization is given by $\max _{P_{2}}\left(P_{2}-w_{2}\right) D^{2}\left(P_{1}, P_{2}\right)$. Her first order condition is $\left(P_{2}-w_{2}\right) D_{2}^{2}+$ $D^{2}=0$. Solving for retailer 2's price when retailer 1 has $\mathrm{RPM}$ gives $P_{2}^{M B}=P_{2}^{M B}\left(P_{1}, w_{2}\right)$.

The manufacturers' game can now be split into two parts. First, consider the producer who is chosen by retailer 2 . The producer so chosen will have maximized

$$
\left(P_{2}^{M B}-w_{2}\right) D^{2}\left(P_{1}, P_{2}^{M B}\right) \quad \text { s.t. } \quad\left(w_{2}-c\right) D^{2}\left(P_{1}, P_{2}^{M B}\right) \geq 0
$$

It is easy to verify that $w_{2}=c$ satifies the Kuhn - Tucker conditions. The intuition behind this result is simple. It says that when faced with an opponent, retailer 1 , whose hands are tied (her price is contractually determined), the best strategy is to retain maximum 
flexibility by buying at the lowest wholesale price available. There is no commitment value in choosing $w_{2}>c$. The only reason to have done so would have been to induce $P_{1}$ to be higher. This is not possible when retailer 1 has chosen RPM.

Now consider retailer 1's supplier. To secure his place on the shelf he must choose $P_{1}$ to maximize retailer 1's profits subject to his zero profit condition. Formally, $P_{1}$ is chosen to maximize $\left(P_{1}-c\right) D^{1}\left(P_{1}, P_{2}^{M B}\left(P_{1}, w_{2}\right)\right)$. The first order condition gives

$$
\left[\left(P_{1}-c\right) D_{1}^{1}+D^{1}\right]+\left(P_{1}-c\right) D_{2}^{1} \frac{\partial P_{2}^{M B}}{\partial P_{1}}=0
$$

Without the second term, and with $c$ substituted for $w_{2}$, the solution would give $P^{B}$. But (9) says that $i$ 's supplier takes into account retailer 2's price response. The second term will be positive if and only if $\partial P_{2}^{M B} / \partial P_{1}>0$. This can easily be verified by applying the implicit function theorem to retailer 2's first order condition.

$$
\frac{\partial P_{2}^{M B}}{\partial P_{1}}=\frac{-\left[\left(P_{2}-w_{2}\right) D_{21}^{2}+D_{1}^{2}\right]}{\left(P_{2}-w_{2}\right) D_{22}^{2}+2 D_{2}^{2}}=-\frac{\pi_{21}^{2}}{\pi_{22}^{2}}>0
$$

Because of the second term the manufacturer will choose $P_{1}>P_{1}^{B B}(c, c)$. At $P_{1}=P_{1}^{B B}(c, c)$, $P_{2}^{M B}=P_{2}^{B B}(c, c)$, and $\left(P_{1}^{B B}-c\right) D_{1}^{1}+D^{1}=0$. The positive second term indicates that profit can be increased with a higher $P_{1}$. Therefore let $P_{1}^{M B}$ solve (9). Then the downstream equilibrium prices and profits when firm 1 chooses RPM and firm 2 remains flexible can be denoted

$$
P^{M}=\left(P_{1}^{M B}, P_{2}^{M B}\left(P_{1}^{M B}, c\right)\right), \quad \Pi^{M}=\left(\pi^{1}\left(P^{M} ; F_{1}=0\right), \pi_{2}\left(P^{M} ; F_{2}=0\right)\right)
$$

The following two lemmas establish that prices and profits for both retailers will be higher in this case than in the benchmark case. These results will be used to show that the scenario where neither retailer chooses RPM cannot be an equilibrium of the game. 
lemma $1 P_{2}^{M B}\left(P_{1}^{M B}, c\right)>P_{2}^{B B}(c, c)$

Proof: By the definition of a Nash equilibrium $P_{2}^{B B}(c, c)=P_{2}^{M B}\left(P_{1}^{B B}(c, c), c\right)$. It was shown that $P_{1}^{M B}>P_{1}^{B B}(c, c)$. Since $\partial P_{2}^{M B} / \partial P_{1}>0, P_{2}^{M B}\left(P_{1}^{M B}, c\right)>P_{2}^{B B}(c, c)$. Q.E.D.

lemma $2 \Pi^{M}>\Pi^{B}$

Proof: This is a standard result in the literature on price leader and follower games. In this model the firm choosing RPM acts as a price leader while the uncommitted firm is the price follower. Both retailers earn higher profits than in the benchmark case with simultaneous play.

Proposition 4 At least one retailer will choose to price maintain her product when RPM is legal and fixed fees are not allowed.

Proof: Suppose not. If retailer 2's supplier is charging $w=c$, and not maintaining her retail price, other suppliers will compete to set dealer 1's price at $P_{1}^{M B}$ and charge c per unit good. By lemma 2 , the resulting profit to retailer $1, \Pi_{1}^{M}$, is greater than $\Pi_{1}^{B}$. Q.E.D.

Proposition 5 Retail prices and profits are higher vis a vis the benchmark case when RPM is legalized and coverage is incomplete, i.e. one firm chooses not to use RPM.

Proof: This follows immediately from lemmas 1 and 2. Q.E.D.

Since incomplete RPM coverage Pareto dominates price maintenance at both outlets in the two player game, it can be argued that the former outcome will be observed. Suppose retailer 1 were forced to choose RPM, but retailer 2 had free choice. With pre-play communication the reasoning is as follows : retailer 1 tells retailer 2 that she will choose $P_{1}=P_{1}^{M B}$. If 
she is believed, " 2 " will choose no RPM and $w_{2}=c$. Knowing this, " 1 " will play $P_{1}=P_{1}^{M B}$. So far, this is just her half of the Nash equilibrium. But simultaneously retailer 2 will be saying to "1" that she will choose no RPM, $w_{2}=c$. Given this, " 1 " will choose $P_{1}=P_{1}^{M B}$. Therefore the case where both retailers impose RPM is not likely to be observed.

The intuition in this section generally and in proposition 5 in particular is that legalizing RPM is tantamount to allowing retailers to commit to prices. In their attempts to secure retail shelf space, the manufacturers act to increase downstream profits by finding the Stackelberg pricing equilibrium. Both prices and profits will be higher as a result.

\section{With RPM and Slotting Allowances}

In this section, I allow producers to include fixed fees and RPM as part of their sales contracts. As before there are three possibilities: either zero, one, or both firms will use RPM. Before proceeding to characterize the equilibria in this section, the following two lemmas will prove useful.

lemma 3 If retailer 2 chooses a two-part tariff contract, retailer 1 will be indifferent between a supplier who maximizes her profit by RPM and a supplier who maximizes her profit via a two-part tariff.

Proof: I will show that a solution to the first order conditions of one maximization problem will also solve the first order conditions of the second maximization problem.

Consider a supplier who maximizes retailer 1's profits by setting $P_{\mathbf{1}}$. His problem is

$\max _{P_{1}}\left(P_{1}-c\right) D^{1}\left(P_{1}, P_{2}^{M B}\left(P_{1}, w_{2}\right)\right)$. The first order condition is given by (9). Substituting 
the expression for $\partial P_{2}^{M B} / \partial P_{1}$ and rearranging gives

$$
\begin{array}{r}
{\left[\left(P_{1}-c\right) D_{1}^{1}\left(P_{1}, P_{2}^{M B}\left(P_{1}, w_{2}\right)\right)+D^{1}\left(P_{1}, P_{2}^{M B}\left(P_{1}, w_{2}\right)\right)\right] \pi_{22}^{2}} \\
-\left(P_{1}-c\right) D_{2}^{1}\left(P_{1}, P_{2}^{M B}\left(P_{1}, w_{2}\right)\right) \pi_{21}^{2}=0
\end{array}
$$

Let $P_{1}=\bar{P}_{1}$ solve this equation.

Now consider a supplier who maximizes retailer 1's profits by setting $w_{1}$ and $\boldsymbol{F}_{1}$. His problem is

$$
\begin{array}{r}
\max _{w_{1}, F_{1}}\left(P_{1}^{B B}\left(w_{1}, w_{2}\right)-w_{1}\right) D^{1}\left(P_{1}^{B B}\left(w_{1}, w_{2}\right), P_{2}^{B B}\left(w_{1}, w_{2}\right)\right)-F_{1} \\
\text { s.t. }\left(w_{1}-c\right) D^{1}\left(P_{1}^{B B}\left(w_{1}, w_{2}\right), P_{2}^{B B}\left(w_{1}, w_{2}\right)\right)+F_{1}=0
\end{array}
$$

The first order condition is

$$
\begin{gathered}
{\left[\left(P_{1}^{B B}-c\right) D_{1}^{1}\left(P_{1}^{B B}, P_{2}^{B B}\right)+D^{1}\left(P_{1}^{B B}, P_{2}^{B B}\right)\right] \frac{\partial P_{1}^{B B}}{\partial w_{1}}} \\
+\left(P_{1}^{B B}-c\right) D_{2}^{1}\left(P_{1}^{B B}, P_{2}^{B B}\right) \frac{\partial P_{2}^{B B}}{\partial w_{1}}=0
\end{gathered}
$$

Substituting the expressions for $\partial P_{1}^{B B} / \partial w_{1}$ and $\partial P_{2}^{B B} / \partial w_{1}$ and rearranging gives

$$
\begin{gathered}
{\left[\left(P_{1}^{B B}-c\right) D_{1}^{1}\left(P_{1}^{B B}, P_{2}^{B B}\right)+D^{1}\left(P_{1}^{B B}, P_{2}^{B B}\right)\right] \pi_{22}^{2}} \\
-\left(P_{1}^{B B}-c\right) D_{2}^{1}\left(P_{1}^{B B}, P_{2}^{B B}\right) \pi_{21}^{2}=0
\end{gathered}
$$

Now compare (12) and (14). By setting $w_{1}$ such that $P_{1}^{B B}\left(w_{1}, w_{2}\right)=\bar{P}_{1}$ and recalling that $P_{2}^{B B}\left(w_{1}, w_{2}\right)=P_{2}^{M B}\left(P_{1}^{B B}\left(w_{1}, w_{2}\right), w_{2}\right)$ by the definition of $P_{2}^{B B}$, the solutions to (12) will also be solutions to (14) and vice versa. Plugging $\bar{P}_{1}$ and $P_{1}^{B B}\left(w_{1}, w_{2}\right)$ into their respective profit functions, it is seen that retailer 1 will be indifferent between the two cases. Q.E.D. 
lemma 4 If retailer 1 chooses an RPM contract, retailer 2 will be be indifferent between a supplier who maximizes her profit by RPM and a supplier who maximizes her profit via a two-part tariff.

Proof: As before I will show that the solution to the first order conditions of one maximization problem will also solve the first order conditions of the second maximization problem.

Consider a supplier who maximizes retailer 2 's profit by setting $P_{2}$. His problem is $\max _{P_{2}}\left(P_{2}-c\right) D^{2}\left(P_{1}, P_{2}\right)$. Let $P_{2}=\bar{P}_{2}$ be the solution.

Now consider a supplier who maximizes retailer 2's profit by setting $w_{2}$ and $F_{2}$. His problem is

$$
\begin{array}{r}
\max _{w_{2}, F_{2}}\left(P_{2}^{M B}\left(P_{1}, w_{2}\right)-w_{2}\right) D^{2}\left(P_{1}, P_{2}^{M B}\left(P_{1}, w_{2}\right)\right)-F_{2} \\
\text { s.t. }\left(w_{2}-c\right) D^{2}\left(P_{1}, P_{2}^{M B}\left(P_{1}, w_{2}\right)\right)+F_{2}=0
\end{array}
$$

By setting $w_{2}$ such that $P_{2}^{M B}\left(P_{1}, w_{2}\right)=\bar{P}_{2}$, the solution to the RPM maximization problem can be replicated. Similarly, by setting a maintained price equal to $P_{2}^{M B}\left(P_{1}, w_{2}\right)$, the solution to the two-part tariff maximization problem can be replicated. Q.E.D.

Proposition 6 There are three equilibrium outcomes in the game in which fixed fees and RPM are allowed.

Proof: Consider the three possibilities. If RPM is not observed, then by application of lemma three, the slotting allowance outcome of section IV is an equilibrium. It is also unique.

From lemma four, the outcome in which both retailers choose RPM and price at the benchmark level is an equilibrium. Allowing fixed fees when RPM is used by both stores is 
of no consequence since the wholesale price set equal to supplier marginal cost is sufficient to extract producer surplus.

Using lemmas three and four, the outcome found in section $\mathrm{V}$ in which only one retailer chooses RPM is also an equilibrium when fixed fees are allowed. It is easy to show that the retailer who remains price flexible will choose to buy at $w=c$ and $F=0$. Likewise the retailer using RPM does not need a fixed fee to capture her supplier's profit.

Therefore the three outcomes are: both retailers choose slotting allowance contracts with prices and profits $\left(P^{S}, \Pi^{S}\right)$; both retailers choosing RPM contracts with prices and profits $\left(P^{B}, \Pi^{B}\right)$; and only one retailer choosing RPM with prices and profits $\left(P^{M}, \Pi^{M}\right)$. Q.E.D.

I have shown that when both retailers sign slotting allowance contracts, retail prices will be higher and sales lower relative to the benchmark case where producer wholesale prices were set at marginal cost.

I have also shown that when both retailers choose resale price maintenance, the outcome will replicate the benchmark case, whereas if only one firm uses RPM, prices and profits will be higher for both firms.

The next step is to compare prices and profits in the slotting allowances equilibrium with the corresponding values when RPM is observed at only one store. The following proposition will assess this case.

Consider the case where both retailers receive slotting allowances. Define $w_{i}=r_{i}\left(w_{j}\right)$ to be retailer $i$ 's profit maximizing wholesale price when $j$ has chosen $w_{j}$. If $d r_{i} / d w_{j}>0$, then i's producer wholesale price reaction function is said to be upward sloping. ${ }^{21}$

\footnotetext{
${ }^{21}$ This will be true with linear demands. Implicitly differentiating (4) gives $d r_{i} / d w_{j}=$ $\left(\partial P_{i}^{B B} / \partial w_{j}\right) D_{j}^{i} D_{i}^{j} /\left(2 D_{i}^{i} D_{j}^{j}-\left(\partial P_{i}^{B B} / \partial w_{i}\right) D_{j}^{i} D_{i}^{j}\right)>0$ by assumption 1 . In general, the expression for $d r_{i} / d w_{j}$ will contain third derivatives of the retail profit functions and cannot be signed.
} 
Proposition 7 If producer wholesale price reaction functions are upward sloping, retailer prices and profits are higher in the slotting allowance equilibrium than they are in the equilibrium where one retailer chooses $R P M$. That is $P^{S}>P^{M}$ and $\Pi^{S}>\Pi^{M}$.

Proof: Recall $P^{M}=\left(P_{1}^{M B}, P_{2}^{M B}\right)$. By lemma 3 this equals $\left(P_{1}^{B B}\left(\bar{w}_{1}, c\right), P_{2}^{B B}\left(\bar{w}_{1}, c\right)\right)$ where $\bar{w}_{1}=r_{1}(c) . P^{S}=\left(P_{1}^{B B}\left(w_{1}^{s}, w_{2}^{s}\right), P_{2}^{B B}\left(w_{1}^{s}, w_{2}^{s}\right)\right)$ where $w_{1}^{s}=r_{1}\left(w_{2}^{s}\right)$ and $w_{2}^{s}=r_{2}\left(w_{1}^{s}\right)$. Since $w_{2}^{s}>c, w_{1}^{s}>\bar{w}_{1}$ if $d r / d w>0$. Furthermore $\partial P^{B B} / \partial w_{1}$ and $\partial P^{B B} / \partial w_{2}>0$ for all $w$, by (5). Therefore $P^{S}>P^{M}$.

Now consider retailer profits.

$$
\begin{aligned}
& \Pi_{1}^{M}=\pi^{1}\left(P_{1}^{M B}, P_{2}^{M B}\left(P_{1}^{M B}, c\right) ; F_{1}=0\right) \\
& =\pi^{1}\left(P_{1}^{B B}\left(\bar{w}_{1}, c\right), P_{2}^{M B}\left(P_{1}^{B B}\left(\bar{w}_{1}, c\right), c\right) ; \bar{F}_{1}\right) \text { by lemma } 3 \\
& =\pi^{1}\left(P_{1}^{B B}\left(\bar{w}_{1}, c\right), P_{2}^{B B}\left(\bar{w}_{1}, c\right) ; \bar{F}_{1}\right) \quad \text { by Nash equilibrium } \\
& <\pi^{1}\left(P_{1}^{B B}\left(\bar{w}_{1}, w_{2}^{s}\right), P_{2}^{B B}\left(\bar{w}_{1}, w_{2}^{s}\right) ; \bar{F}_{1}\right) \quad \text { since } \partial \pi^{1} / \partial w_{2}>0 \text { by (12) } \\
& <\pi^{1}\left(P_{1}^{B B}\left(w_{1}^{s}, w_{2}^{s}\right), P_{2}^{B B}\left(w_{1}^{s}, w_{2}^{s}\right) ; F_{1}^{s}\right) \quad \text { since } w_{1}^{s}=r_{1}\left(w_{2}^{s}\right) \\
& =\Pi_{1}^{S}
\end{aligned}
$$

Similarly an analogous proof applies for $\Pi_{2}^{S}>\Pi_{2}^{M}$. Q.E.D.

Since the slotting allowance equilibrium Pareto dominates both RPM equilibrium outcomes, an argument similar to the one given earlier provides an intuitive basis for predicting the observance of rental fees. With pre-play communication, both players will be announcing their slotting allowance preferences. Given the other's announcement, both players will indeed choose $w=w^{s}$. Therefore, unless there are observability or monitoring problems associated with the high wholesale prices that come with these contracts, I would not expect to see RPM used in the two player game when slotting allowances are legal. 
RPM directly commits a firm to a retail price. If both retailers choose RPM, neither can react to her opponent's price. Any advantage of commitment in the penultimate stage is lost, since the pricing game is trivialized. With incomplete coverage, one firm commits itself to a pre-specified price while the second firm is free to react accordingly. Retail prices and profits are higher in this case. With slotting allowances, both retailes commit to high marginal costs, and in the final stage both firms can react to the other's commitment. This combination leads to even higher downstream prices. Thus prices and profits will be highest if both firms are playing a puppy dog strategy. Welfare is lowest in this case.

\section{Welfare}

So far the analysis has shown $\left(P^{S}, \Pi^{S}\right)>\left(P^{M}, \Pi^{M}\right)>\left(P^{B}, \Pi^{B}\right)$. The implication is that both slotting allowances and RPM lower welfare. But important questions remain. By how much do prices rise with RPM (slotting allowances)? In what way do the price differences depend on the perceived differentiation of the retailers? How does the magnitude of the welfare decline compare with the welfare performance of a retail cartel? As a start in answering these questions, I will need to specify a functional form of demand.

Let $D^{i}(P)=(1 / 2)\left(V-(1+\gamma) P_{i}+\gamma P_{j}\right)$. Demand is then characterized by the substitution parameter $\gamma \geq 0$. For unit increases in $P_{i}$, firm i loses $1+\gamma$ in sales. Of this $\gamma$ sales will be diverted to firm $\mathrm{j}$. Thus $\gamma /(1+\gamma)$ represents the increase in $\mathrm{j}$ 's sales as a fraction of i's lost sales. When $\gamma=0$, no sales will be diverted; each retailer is a monopolist. As $\gamma \rightarrow \infty$ the retailers become perfect substitutes. Demand is assumed to be symmetric to simplify computation.

Prices and profits will be calculated for each scenario. These will then be compared 
with each other and with the hypothetical cartel solution. Next a simple index of price performance is developed to gain further perspective on the magnitude of the various price markups. Finally I will look explicitly at social welfare and consider when the use of RPM and slotting allowances will lead to the worst outcomes.

Competitive case: When neither practice is allowed non-cooperative equilibrium retail prices and profits are found by the simultaneous solution to the first order conditions $\pi_{i}^{i}=\left(P_{i}-\right.$ $\left.w_{i}\right) D_{i}^{i}+D^{i}=0$. Straightforward computations give

$$
P^{B}=P^{B B}(c, c)=\frac{V+(1+\gamma) c}{2+\gamma} \quad ; \quad \Pi^{B}=\pi^{i}\left(P^{B} ; F_{i}=0\right)=\frac{(1+\gamma)(V-c)^{2}}{2(2+\gamma)^{2}}
$$

for both retailers. Policy discussion should focus around this case since it is the first best from society's viewpoint.

Slotting Allowance case: If both firms choose slotting allowances, one can show that each retailer will have

$$
\begin{aligned}
& P^{S}=P^{B B}\left(w_{1}^{s}, w_{2}^{s}\right)=\frac{2(1+\gamma) V+\left(2+4 \gamma+\gamma^{2}\right) c}{4+6 \gamma+\gamma^{2}} \\
& \Pi^{S}=\pi^{i}\left(P^{S} ; F_{i}^{s}\right)=\frac{(1+\gamma)\left(2+4 \gamma+\gamma^{2}\right)(V-c)^{2}}{\left(4+6 \gamma+\gamma^{2}\right)^{2}}
\end{aligned}
$$

Incomplete RPM Coverage case: When RPM is observed at one retail outlet, the equilibrium outcome can be calculated as

$$
\begin{aligned}
& P_{1}^{M}=P_{1}^{M B}=\frac{(2+3 \gamma) V+\left(2+5 \gamma+2 \gamma^{2}\right) c}{2\left(2+4 \gamma+\gamma^{2}\right)} \\
& P_{2}^{M}=P_{2}^{M B}\left(P_{1}^{M B}, c\right)=\frac{\left(4+10 \gamma+5 \gamma^{2}\right) V+\left(4+14 \gamma+15 \gamma^{2}+4 \gamma^{3}\right) c}{4(1+\gamma)\left(2+4 \gamma+\gamma^{2}\right)} \\
& \Pi_{1}^{M}=\pi^{1}\left(P^{M} ; F_{i}=0\right)=\frac{(2+3 \gamma)^{2}(V-c)^{2}}{16(1+\gamma)\left(2+4 \gamma+\gamma^{2}\right)}
\end{aligned}
$$




$$
\Pi_{2}^{M}=\pi^{2}\left(P^{M} ; F_{i}=0\right)=\frac{\left(4+10 \gamma+5 \gamma^{2}\right)^{2}(V-c)^{2}}{32(1+\gamma)\left(2+4 \gamma+\gamma^{2}\right)^{2}}
$$

Cartel case: This case was not considered earlier, but it is useful to derive for comparison sake. Suppose both firms could cooperate and achieve the collusive outcome. They would find the optimal $P^{c}$ and $\Pi^{c}$ to be

$$
P^{c}=\frac{V+c}{2} \quad ; \quad \Pi^{c}=\frac{(V-c)^{2}}{8}
$$

I will now compare the alternative cases. Some simple conclusions can be summarized in the following proposition.

Proposition 8 When $\gamma=0$, all prices and profits are equal to the cartel outcome. For given $\gamma>0,\left(P^{c}, \Pi^{c}\right)>\left(P^{S}, \Pi^{S}\right)>\left(P^{M}, \Pi^{M}\right)>\left(P^{B}, \Pi^{B}\right)$. With the exception of the cartel outcome, all prices and profits are monotonically decreasing in $\gamma$. Finally, marginal cost pricing and zero profits prevail as $\gamma \rightarrow \infty$.

These results can be easily verified. As the retailers become more homogeneous, their noncooperative ability to sustain $P>c$ and $\Pi>0$ declines. At the extreme points the expected cartel and Bertrand pricing homogeneous product outcomes arise, while for intermediate $\gamma$, the cases can be unambiguously ranked as found in the earlier theory.

What about the magnitude of the price markups? For given $\mathrm{V}$, $\mathrm{c}$, and $\gamma$ the exact prices can be determined for each case. Price differences and percentage markups could then be found. However this is a cumbersome method. By constructing a simple price index, the need to consider $\mathrm{V}$ and $\mathrm{c}$ is eliminated, thereby allowing one to focus on how the markups change with respect to $\gamma$. Define

$$
I=\frac{P-c}{P^{c}-c} . \quad \text { where } \quad P=\left(P^{B}, P^{M}, P^{S}\right)
$$


This index looks at the absolute markup of the equilibrium price over supplier marginal cost divided by the markup of the collusive price over supplier marginal cost. Since $P<P^{c}$, $0 \leq I \leq 1$. As $\gamma \rightarrow \infty, I \rightarrow 0$ and as $\gamma \rightarrow 0, I \rightarrow 1$. This formulation is convenient to use since it abstracts from $\mathrm{V}$ and c. As $I$ increases, industry performance decreases.

Table 1 presents results from selected $\gamma$. The numbers at the top of the table correspond to individual values of $\gamma$. The rows correspond to the respective index calculations. $I^{B}$ represents the competitive case. $I_{i}^{M}$ represents firm i in the non-universal coverage RPM case. $I^{S}$ corresponds to the slotting allowance case.

\section{Insert table 1 here}

When $\gamma=18,(95 \%$ of firm i's lost sales are diverted to firm $\mathrm{j}$ when i's price increases) non- cooperative competition, barring both practices, leads to prices which are $10 \%$ of the distance between the cartel and perfect competition points. With RPM the price maintained firm extends this to $14.1 \%$ while her competitor has a scaled markup of $11.9 \%$. With slotting allowances the equilibrium prices are marked up by $17.4 \%$. When $\gamma=38(97 \%$ sales diversion), the benchmark case has a scaled markup of $5 \%$. Slotting allowances would lead to a $9.3 \%$ markup, while the RPM case leads to a $7.3 \%$ and $6.1 \%$ markup for the RPM firm and her rival respectively.

Such calculations are meant to be illustrative of the magnitude of price rises one could expect under different regimes. Alternatively one could focus on the precise welfare differences among the various scenarios. Price rises in themselves only signal decreases in welfare. One may ask when the resulting welfare decline is greatest. Are the gains to challenging these shelf space practices more when retailers have a high product substitution or a low 
one?

To answer this, I need to consider the form of the utility function. Ignoring income effects, and aggregating the preferences of consumers, the linear demands used in this chapter can be derived from the following quadratic function. ${ }^{22}$

$$
U=V q-\frac{1}{2} q^{2}-\frac{2 \sigma^{2}}{1+2 \gamma}-\sum_{i=1}^{2} P_{i} q_{i}
$$

where $q=D_{1}+D_{2}$ and $\sigma^{2}=\left(\frac{D_{1}-D_{2}}{2}\right)^{2}$. Defining social welfare as the sum of consumer surplus and profits, gives $S W=V q-\frac{1}{2} q^{2}-\frac{2 \sigma^{2}}{1+2 \gamma}-c \sum_{i=1}^{2} q_{i}$. Let $\Delta S W$ be the percent change in welfare when moving from the competitive case to either the slotting $\left(\Delta S W_{S}\right)$ or RPM case $\left(\Delta S W_{M}\right)$.

Proposition $9 \Delta S W_{S} \leq \Delta S W_{M} \leq 0$ with equality at $\gamma=0$ and $\gamma=\infty$.

These results can be verified by straightforward algebra. For all $\gamma$ between 0 and $\infty$, welfare declines when either or both practices are allowed. The change in welfare is zero when $\gamma=0$ or $\gamma=\infty$. At $\gamma=0$ the retailers are already able to reach the monopoly outcome. The price enhancing features of slotting allowances or RPM are not needed. At $\gamma=\infty$, price increases above cost cannot be sustained as consumers view the two retailers as perfect substitutes.

When will society be hurt most by the shelf space practices? Minimizing $\Delta S W$ with respect to $\gamma$, one can show that welfare decline is greatest when $\gamma \approx 2$. This is true for both the slotting allowance and RPM cases. Figures 1 and 2 depict $\Delta S W$ when $0 \leq \gamma \leq 40$. The vertical axes measure the percent change in utility. With linear demands the gains to barring both practices increases rapidly as $\gamma$ goes from 0 to 2 and thereafter declines in a

\footnotetext{
${ }^{22}$ See Shubik (1980).
} 
logarithmic fashion. At their worse, the social welfare loss relative to the competitive case is $3 \%$ and $1.4 \%$ for the slotting allowance and RPM cases respectively.

By comparison, figure 3 shows the percent welfare loss of the cartel case relative to the competitive case. This loss can reach as high as $25 \%$. Thus although RPM and slotting allowances increase retail prices, their loss is small by comparison.

\section{Conclusion}

I have analyzed slotting allowances and RPM in a model where producers in a perfectly competitive industry compete to obtain shelf space at the retail level. Barring contract observability problems, slotting allowances will be observed in equilibrium. Producers charge a high wholesale price, but give back their profits via up-front payments to retailers. However if the individual supplier - retailer wholesale price terms are unobservable by rivals, then resale price maintenance will be seen, but the coverage will not be universal. If neither RPM or slotting allowances are available, then the equilibrium entails marginal cost wholesale pricing.

The three equilibria can be ranked by the usual social welfare criteria. Marginal cost wholesale pricing without RPM yields the greatest surplus, while the slotting allowance equilibrium gives the worst performance.

Policy issues are usually complex. Slotting allowances are now legal. RPM is currently per-se illegal. One theme of this paper is that the two practices are substitutable. It contributes to the policy debate by demonstrating that both RPM and slotting allowances can be thought of as facilitating practices.

Conventional wisdom suggests that RPM may correct for service externalitites and pro- 
tect against information free - riding and that slotting allowances may help to improve product selection by downstream retailers who are uncertain of demand. It is shown here that these efficiency claims must be balanced against the possible price raising potential of these practices through their strategic use. 


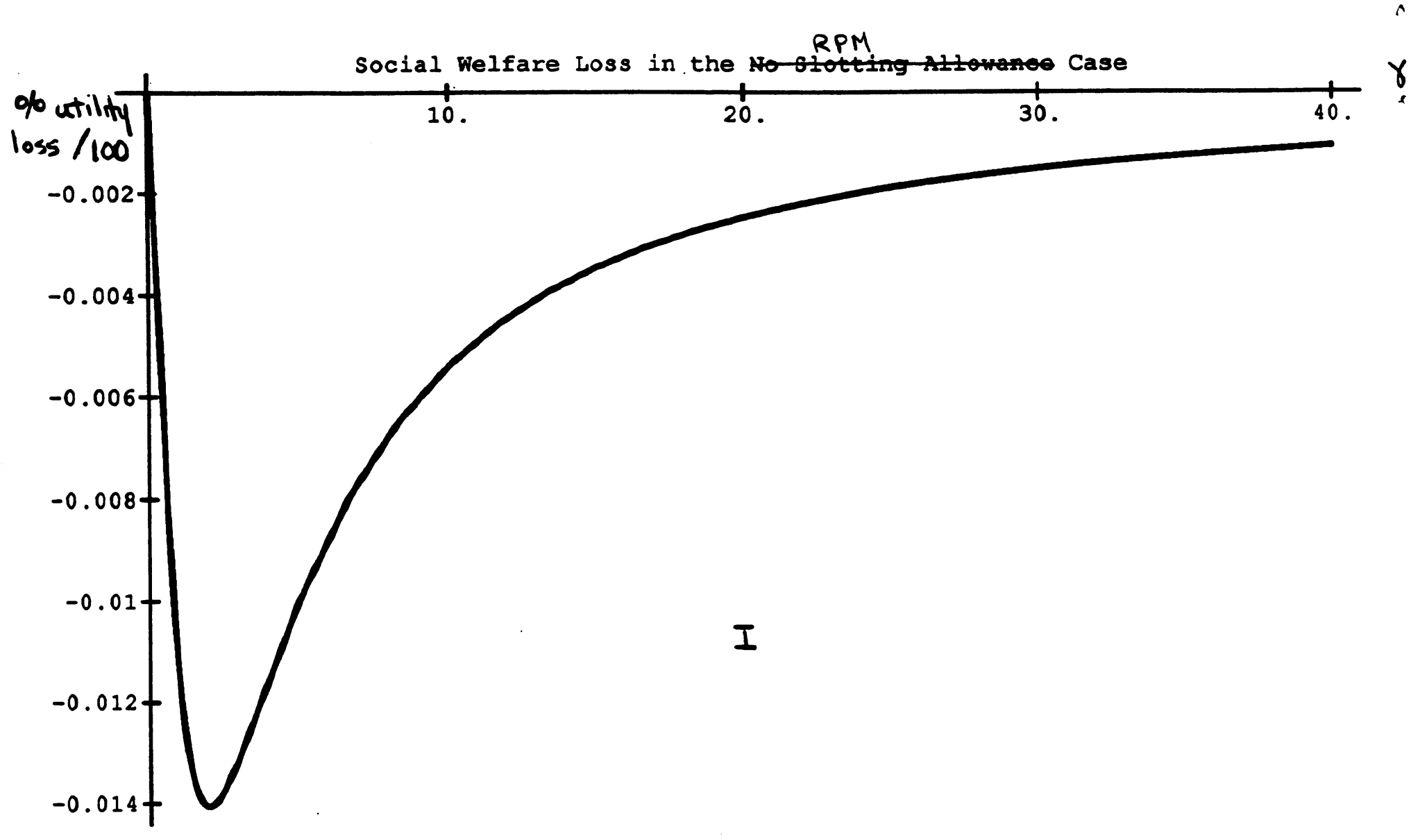




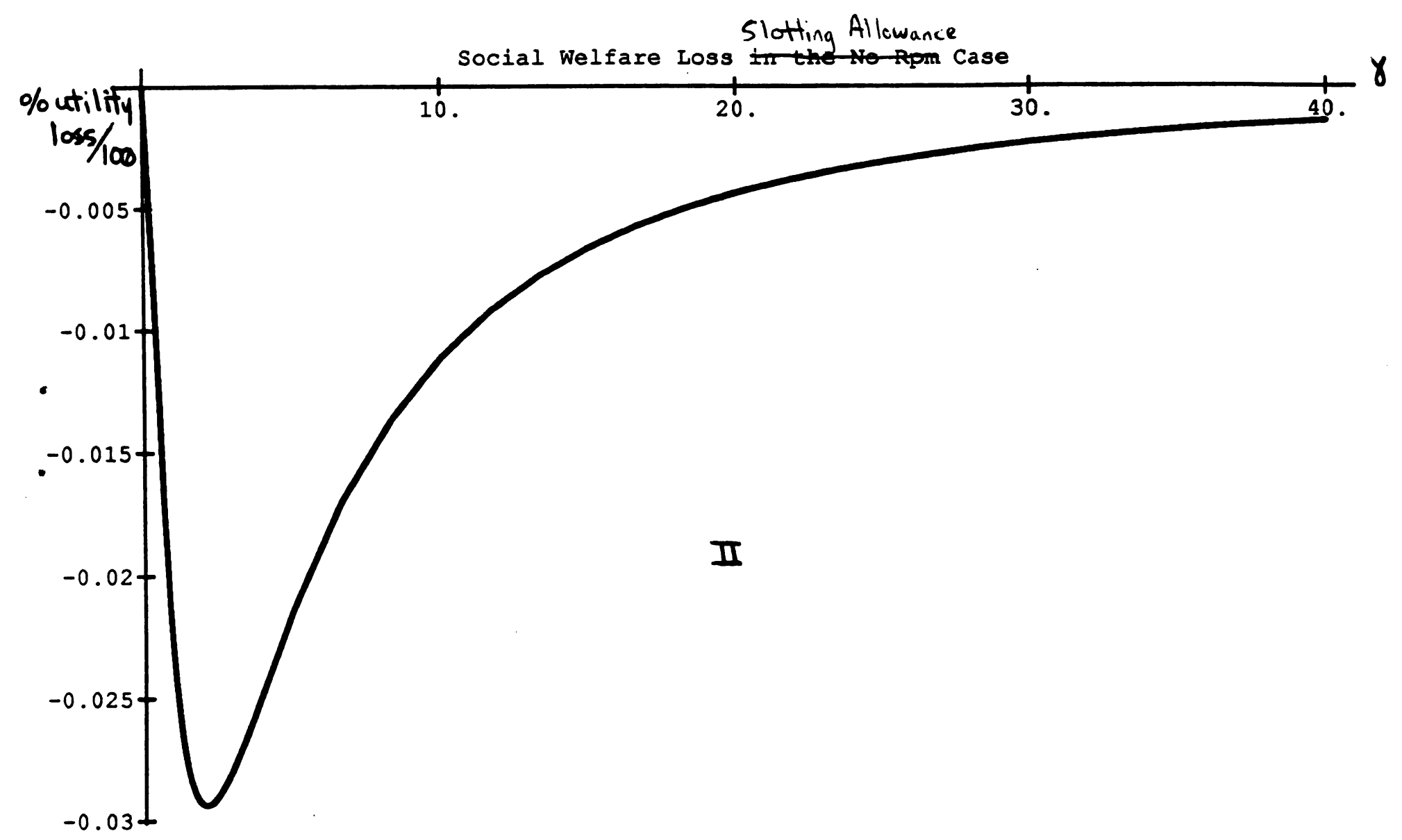




\section{BIBLIOGRAPHY}

Adverising Age (1987), "Grocer 'Fee' Hampers New Product Launches," August 3, page 1.

Bonanno, Giacomo and John Vickers (1988), "Vertical Separation," Journal of Industrial Economics, Vol. 36, No. 3, March, pp. 257-265.

Chicago Tribune (1988), "Route to Grocer's Shelves Toll Road for Food Firms," section 7, January 24 , page 1 .

Fershtman, Chaim and Kenneth Judd (1987), "Equilibrium Incentives in Oligopoly," American Economic Review, Vol. 77, No.5, December, 927 - 940.

Friedman, James (1983), Oligopoly Theory, Cambridge University Press.

Fudenberg, Drew and Jean Tirole (1984), "The Fat-Cat Effect, The Puppy-Dog Ploy, and the Lean and Hungry Look," American Economic Review, Vol. 74, No. 2, May, 361366 .

Johnson, Gerry ed. (1987), Business Strategy and Retailing, John Wiley and Sons Ltd.

Katz, Michael (1986), "Game-Playing Agents with Unobservable Contracts," working paper, University of California at Berkeley.

New York Times (1988), "High Court Backs Discounter Curbs by Manufacturers," May 3, page 1.

Porter, Michael (1976), Interbrand Choice, Strategy, and Bilateral Market Power, Harvard University Press.

Salop, Steve (1986), "Practices that (Credibly) Facilitate Oligopoly Coordination," in New Developments in the Analysis of Market Structure, Joseph Stiglitz and G. Frank Mathewson, eds., MIT Press.

Shubik, Martin (1980), Market Structure and Behavior, Harvard University Press.

Shapiro, Carl (1985), "Patent Licensing and R\&D Rivalry," American Economic Review, Vol. 75, May, pp. 25-30. 


\begin{tabular}{|c|c|c|c|c|c|}
\cline { 2 - 6 }$\gamma$ & 1 & 2 & 10 & 18 & 38 \\
\cline { 2 - 6 }$I^{B}$ & .667 & .500 & .167 & .100 & .050 \\
\cline { 2 - 6 } & & & & & \\
$I_{1}^{M}$ & .714 & .571 & .225 & .141 & .073 \\
\cline { 2 - 6 } & & & & & \\
$I_{2}^{M}$ & .679 & .524 & .193 & .119 & .061 \\
\cline { 2 - 6 } & & & & & \\
$I^{S}$ & .727 & .600 & .268 & .174 & .093 \\
\cline { 2 - 6 }
\end{tabular}

Table 1: 


\section{Recent CREST Working Papers}

89-01: Mark Bagnoli, Severin Borenstein, "Carrot and Yardstick Regulation: Enhancing Market Performance with Output Prizes," October, 1988.

89-02: Ted Bergstrom, Jeffrey K. MacKie-Mason, "Some Simple Analytics of Peak-Load Pricing," October, 1988.

89-03: Ken Binmore, "Social Contract I: Harsanyi and Rawls," June, 1988.

89-04: Ken Binmore, "Social Contract II: Gauthier and Nash," June, 1988.

89-05: Ken Binmore, "Social Contract III: Evolution and Utilitarianism," June, 1988.

89-06: Ken Binmore, Adam Brandenburger, "Common Knowledge and Game Theory," July, 1989.

89-07: Jeffrey A. Miron, "A Cross Country Comparison of Seasonal Cycles and Business Cycles," November, 1988.

89-08: Jeffrey A. Miron, "The Founding of the Fed and the Destabilization of the Post-1914 Economy," August, 1988.

89-09: Gérard Gaudet, Stephen W. Salant, "The Profitability of Exogenous Output Contractions: A Comparative-Static Analysis with Application to Strikes, Mergers and Export Subsidies," July, 1988.

89-10: Gérard Gaudet, Stephen W. Salant, "Uniqueness of Cournot Equilibrium: New Results from Old Methods," August, 1988.

89-11: Hal R. Varian, "Goodness-of-fit in Demand Analysis," September, 1988.

89-12: Michelle J. White, "Legal Complexity," October, 1988.

89-13: Michelle J. White, "An Empirical Test of the Efficiency of Liability Rules in Accident Law," November, 1988.

89-14: Carl P. Simon, "Some Fine-Tuning for Dominant Diagonal Matrices," July, 1988.

89-15: Ken Binmore, Peter Morgan, "Do People Exploit Their Bargaining Power? An Experimental Study," January, 1989.

89-16: James A. Levinsohn, Jeffrey K. MacKie-Mason, "A Simple, Consistent Estimator for Disturbance Components in Financial Models," April 25, 1989.

89-17: Hal R. Varian, "Sequential Provision of Public Goods," July, 1989.

89-18: Hal R. Varian, "Monitoring Agents with Other Agents," June, 1989.

89-19: Robert C. Feenstra, James A. Levinsohn, "Distance, Demand, and Oligopoly Pricing," July 17, 1989.

89-20: Mark Bagnoli, Shaul Ben-David, Michael McKee, "Voluntary Provision of Public Goods," August, 1989.

89-21: N. Gregory Mankiw, David Romer, Matthew D. Shapiro, "Stock Market Forecastability and Volatility: A Statistical Appraisal," August, 1989.

89-22: Arthur J. Robson, "Efficiency in Evolutionary Games: Darwin, Nash and the Secret Handshake," 1989 .

89-23: Mark Bagnoli, Ted Bergstrom, "Log-Concave Probability and Its Applications," September 7, 1989.

89-24: Gérard Gaudet, Stephen W. Salant, "Towards a Theory of Horizontal Mergers," July, 1989.

89-25 (evolved from 87-35): Stephen W. Salant, Eban Goodstein, "Predicting Committee Behavior in Majority-Rule Voting Experiments," July, 1989.

89-26: Ken Binmore, Martin J. Osborne, Ariel Rubinstein, "Noncooperative Models of Bargaining," 1989.

89-27: Avery Katz, "Your Terms or Mine? The Duty to Read the Fine Print in Contracts," February 19, 1989 . 


\section{Recent CREST Working Papers}

90-01: Hal R. Varian, "A Solution to the Problem of Externalities and Public Goods when Agents are Well-Informed," January 17, 1990.

90-02: Hal R. Varian, "Sequential Provision of Public Goods," January 17, 1990.

90-03: Hal R. Varian, “Goodness-of-Fit Optimizing Models," December 11, 1989.

90-04: Paul N. Courant, Alan Deardorff, "International Trade with Lumpy Countries, " August 22, 1989.

90-05: Dilip K. Bhattacharyya, Jan Kmenta, "Testing Hypotheses about Regression Coefficients in Misspecified Models," December 15, 1989.

90-06: Greg Shaffer, "Slotting Allowances and Resale Price Maintenance: A Comparison of Facilitating Practices," November 1989.

90-07: Michelle J. White, "Why are Taxes So Complex and Who Benefits?" January 19, 1990.

90-08: Daniel P. O'Brien, "Endogenous Price Leadership: A Bargaining Model of International Telecommunications Settlements," May 1989.

90-09: Mark Bagnoli, Barton L. Lipman, "Stock Price Manipulation Through Takeover Bids," November 1989.

90-10: Ken Binmore, "Bargaining Theory Without Tears," December 1, 1989.

90-11: Hyun Song Shin, "Non-Partitional Information On Dynamic State Spaces and the Possibility of Speculation," December 1989. 

